\title{
Diurnal variation effect in marine magnetometric surveys: clues from surveys in southeast Brazil
}

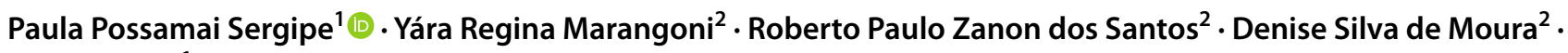 \\ Luigi Jovane ${ }^{1}$
}

Received: 10 March 2021 / Accepted: 30 July 2021 / Published online: 6 August 2021

(c) The Author(s) 2021

\begin{abstract}
The diurnal variation of the magnetic field cannot be predicted or modeled and for that reason, it is monitored during the magnetic surveys, usually by a stationary magnetometer. However, marine surveys have a practical issue with diurnal monitoring, owing to the distance between the survey, stationary magnetometers, and magnetic observatories. This work aims to verify the use of nearby magnetic observatories to estimate the diurnal variation correction in different marine surveys and evaluate its effectiveness. In this study, we selected surveys at the continental shelf near Santos city (Survey 1), continental slope next to the first survey location (Survey 2), continental shelf near Ubatuba city (Survey 3), and Mamanguá ria in the Paraty city (Survey 4), all southeast to the Brazilian coast. The crossing points were implemented to compare the magnetic field values at different times and days at the same measurement point, before and after the correction. Afterwards, we measure the Pearson's Correlation of the raw data and the diurnal corrected data in all crossing points of each survey which showed an improvement after correction by the value approximating to 1 , which indicates a very well correlation. The Ubatuba and Mamanguá surveys allowed comparing the observatory correction results with the base magnetometer results that were rather similar. Our analyses indicate a satisfactory diurnal correction using the observatory data and the crossing points approach, which can be used for every marine magnetometric survey worldwide placed near the coast $(<280 \mathrm{~km})$ that do not have a stationary magnetometer available.
\end{abstract}

Keywords Diurnal variation $\cdot$ Magnetic observatories $\cdot$ Crossing points $\cdot$ Marine surveys

\section{Introduction}

The Earth's magnetic field is formed from the movement of convection currents of the conductive metal fluid in the outer core, which is made up of a $\mathrm{Fe}-\mathrm{Ni}$ alloy and some lighter elements (Zhang et al. 2016). On the Earth's surface, it resembles a dipole field, and it is continually modified by the external magnetic field that results from the interaction with the solar wind, forming the so-called magnetosphere (Lowrie 2007; Telford et al. 1990).

Some of the changes in magnetic field values occur due to the rotation of the Earth and the interaction between solar

Paula Possamai Sergipe

paulapsergipe@gmail.com

1 Oceanographic Institute, University of São Paulo, São Paulo, Brazil

2 Institute of Astronomy, Geophysics and Atmospheric Sciences, University of São Paulo, São Paulo, Brazil radiation and the ionosphere layers (Reeves 2005). Among one of the processes that generate those changes, there is the diurnal variation, which is originated from a current produced by electrically charged particles that move through the Earth's magnetic field. The diurnal variation or magnetic daily variation is an oscillation of the magnetic field on the Earth's surface with a daily period, whose intensity is greater around noon (Lowrie 2007; Reeves 2005). Usually, the diurnal variation has a small amplitude and a smooth pattern, except when the Sun irradiates a more intense flux of ions, producing a phenomenon called magnetic storm. This is characterized by high intensities and frequencies, and it changes the structure of the magnetosphere, being able to last from a few hours to a few days (Panasyuk et al. 2004). During a marine magnetic survey, magnetic storms cannot be corrected from data and usually require the interruption of the data acquisition, because their chaotic behavior do not allow the use of a base magnetometer, since there is no guarantee that the oscillation of the magnetic field is the 
same for its location and the mobile magnetometer (Lowrie 2007; Panasyuk et al. 2004).

The diurnal variation cannot be predicted or modeled so it is measured during magnetic surveys. The data is acquired by a magnetometer (base station or base magnetometer called BASEMAG) in the survey area recording the magnetic field during the entire day. Another possibility is to reoccupy various stations during the day and use this duplicate data to correct the daily data. In some marine surveys, neither of these procedures is applicable. It is too expensive for the ship to redo the magnetometric acquired line. Leaving a base magnetometer in the middle of the ocean is also not practical and the base station is only used when the survey area is close to the coast and it is possible to leave the base in a safe location avoiding noise and disturbances (Melo et al. 2019).

In the literature, there are a few discussions about the diurnal variation correction in marine areas. An experiment conducted by Hill and Mason (1962) showed that the daily variations were greater at sea than at the shore by a factor of about 2. They used a proton precession magnetometer in buoys anchored in 4 positions in the continental slope about $190 \mathrm{~km}$ to the southwest of Land's End, and basically the buoy observations were recorded digitally by heat-sensitive paper since it worked with transistorized block units. The magnetometer worked every $5 \mathrm{~min}$ for almost 7 days. Therefore, these authors suggested that the magnetic field is affected by the tidal motion of the water which induces electrical currents in the sea and generates additional magnetometric noise to the daily variation.

Parkinson and Jones (1979) discussed an issue for the use of base magnetometers at the coast, the geomagnetic coast effect, which is caused by a considerable difference between the sea's electrical conductivity at the sea and at the continent. In this review, the authors tried to evaluate the observations relevance of the relative influence of the electric currents flowing in shallow seawater against the deeper currents, and they used some models to explain the coast effect. Between a few minutes and a few days, they indicated the diurnal variation as the most tenacious phenomena producing a well-defined 24-h period line spectrum.

Buchanan et al. (1996) conducted a study on marine data corrections at equatorial latitudes. In that work, they pursue a simple model of diurnal variation, based on magnetic field measurements, through averaging all measures by day and then averaging again through hours. Moreover, they adjusted their crossing points differences to a supposed variation pattern to construct an experimental curve for the daily variation. Besides that, they also checked their results using magnetic data from two observatories, Addis Ababa $\left(9.03^{\circ} \mathrm{N}\right.$, $\left.38.77^{\circ} \mathrm{E}\right)$ and Bangui $\left(4.44^{\circ} \mathrm{N}, 18.57^{\circ} \mathrm{E}\right)$. Accordingly, we used a procedure similar to the one proposed by the authors (cit. refer.) to evaluate our data.
This work aims to perform a qualitative analysis after correction of diurnal variation in different marine surveys, using a nearby magnetic observatory. The results were checked by comparing crossing points values doing a Pearson's Correlation analysis before and after correction. Furthermore, we were able to compare the diurnal variation correction results given by the observatory with the results given by a base magnetometer correction, since two marine surveys had it available. In this study, we use data acquired at the southeast Brazilian coast at continental shelf near to Santos coast (São Paulo State, Brazil) (Survey 1), continental slope also along Santos Margin (Survey 2), continental shelf near to Ubatuba coast (São Paulo State, Brazil) (Survey 3), and Mamanguá Bay in Ilha Grande (Rio de Janeiro State, Brazil) (Survey 4) (Fig. 1). All these marine surveys had acquired data on different years with the same marine magnetometer and were carried out in more than one day time. Those datasets allowed us to observe the influence of diurnal variation on marine data.

\section{Magnetometric data and survey areas}

The magnetometer used in all surveys of this work is the SeaSPY2 by Marine Magnetics, an Overhauser marine magnetometer with a resolution of approximately $0.1 \mathrm{nT}$. It measures the intensity of the magnetic field with a sample range between 4 and $0.1 \mathrm{~Hz}$. The data rate for the surveys is $1 \mathrm{~Hz}$, which corresponds to $5-10 \mathrm{~m}$ between data samples along with the profiles.

The BASEMAG was a GSM-19 Overhauser magnetometer with a resolution of $0.01 \mathrm{nT}$ and $\pm 0.1 \mathrm{nT}$ of accuracy (Melo 2019), with sampling data every $3 \mathrm{~min}$. On the Ubatuba survey (Survey 3 in Fig. 1a), the BASEMAG was located in the Oceanographic Institute research base of the University of São Paulo (IO-USP) in Ubatuba city. On the Mamanguá survey (Survey 4 in Fig. 1a), the BASEMAG was placed on the Mamanguá Hostel.

\section{Continental shelf near Santos (SP): January 21st and January 24th, 2018}

The data of Surveys 1 and 2 were acquired during a campaign, onboard the research ship R/V Alpha Crucis from IOUSP. The magnetometer was towed at approximately $270 \mathrm{~m}$ to avoid magnetic noise generated by the ship itself through the operation of motors and hull of metallic material. The data were acquired continuously during the survey and was only discontinued when the vessel stopped for collecting cores.

The Survey 1 is located at the continental shelf southeast to the coast of Santos (São Paulo State, SP), extending for approximately $200 \mathrm{~km}$ between the coast and the 

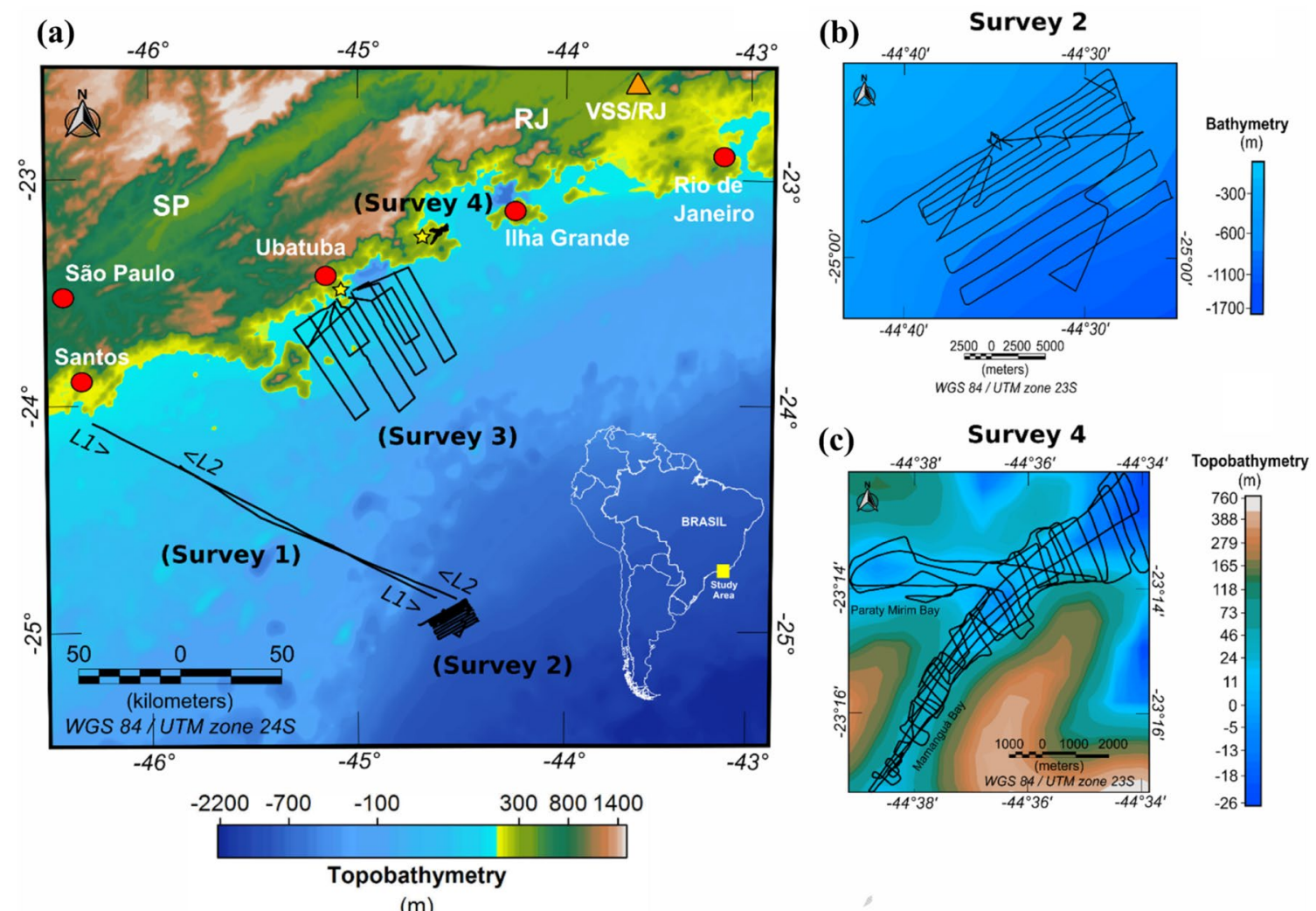

Fig. 1 Topobathymetric maps obtained by Shuttle Radar Topographic Mission (SRTM) version 7, with 30 arc-sec of resolution ( 900 m). a Are the magnetometric surveys location used to analyze the diurnal variation, all in the southeast Brazilian coast. The continental shelf southeast Santos coast (SP) survey is Survey 1, with lines L1 and L2 representing the one way to the slope and the return to Santos coast, respectively (details in Fig. 2). The continental slope survey following this first one is Survey 2, with lines acquisition details in $\mathbf{b}$. The

upper portion of the slope, where the depth rises until almost $400 \mathrm{~m}$ (Survey 1 in Fig. 1a). The profile L1 was acquired on January 21st from 02:09 a.m. until 04:09 p.m., from coast to slope (Fig. 2a) and the L2 was measured on January 24th, from 01:00 a.m. until 10:45 a.m., 2018, from slope to coast (Fig. 2b). These two profiles are located in the Santos Basin, and it is suggested that this basement's portion at Santos shelf is composed of NE-SW structures (Pereira and Macedo 1990; Mohriak 2003). Both profiles are presented in Fig. 2.

\section{Continental slope near Santos (SP): January 21 st to January 23rd, 2018}

The Survey 2 is located at the continental slope southeast of Santos (SP) (Survey 2 in Fig. 1a). The data were acquired during the same cruise as Survey 1. Approximately 325 linear $\mathrm{km}$ of data were collected, with lines almost perpendicular to the continental slope (Fig. 1b). The distance between lines was $1500 \mathrm{~m}$ with some infill continental shelf near to Ubatuba coast (SP) survey is Survey 3. And the continental shelf near to Mamanguá ria survey, between Ubatuba city (São Paulo State, SP) and Ilha Grande (Rio de Janeiro State, RJ) is Survey 4, with acquisition lines details in c. The Vassouras Magnetic Observatory localization (VSS/RJ) is indicated by the yellow triangle, and the approximate location of the base magnetometer (BASEMAG) of the Surveys 3 and 4 is showed by the yellow star. The main cities cited in this work are marked by a red circle

lines (750 $\mathrm{m}$ apart) in the north part of the grid. In Fig. 3, we show one raw profile acquired at this survey on January 23rd, 2018.

\section{Continental shelf near Ubatuba (SP): March 2nd to 5th and May 9th to 11th, 2017}

The Survey 3 is located between São Sebastião Island and Ubatuba coast, north coast of SP, southeast of Brazil (Survey 3 in Fig. 1a). Two surveys were taken with Veliger II wooden boat for collecting data between March 2nd and 5th, and May 9th and 11th, 2017, acquiring approximately $750 \mathrm{~km}$ of data. The magnetometer towfish used a payout cable of $50 \mathrm{~m}$. The survey lines were preferably in NW-SE directions, to cross perpendicularly the known geological structures. Figure 4 shows one raw magnetic profile acquired at this survey on March 3rd, 2017. 

profiles of Survey 1 -Continental shelf near Santos coast survey, where a is the Profile L1, acquired on January 21st, 2018, and b is the Profile L2, acquired on January 24th, 2018, both with the measurement a shows an interruption in the magnetometer's acquisition caused by gravity core sampling, and the blue and green two approximate locations of crossing points
Fig. 2 Magnetic anomaly of hour (UTC). The red circle in circles at profiles indicates the

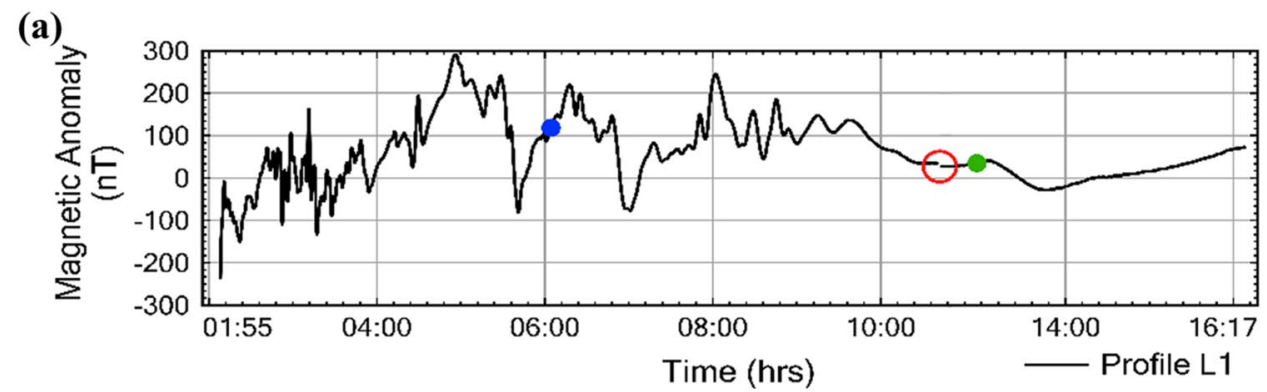

(b)
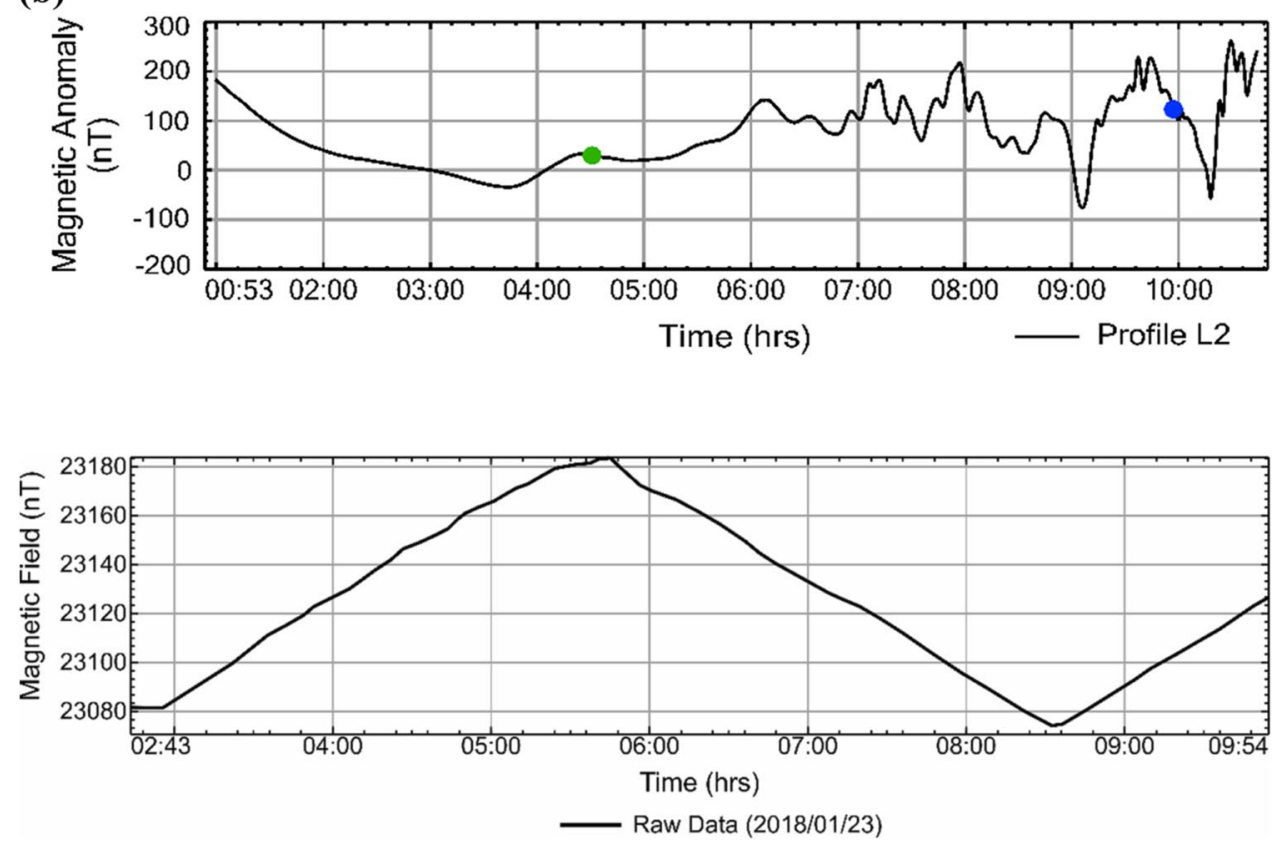

Fig. 3 Magnetic profile of Survey 2 -Continental slope near Santos coast survey, acquired on January 23rd, 2018

Fig. 4 Magnetic profile of Survey 3 -Continental shelf near to Ubatuba coast (SP), acquired on March 3rd, 2017

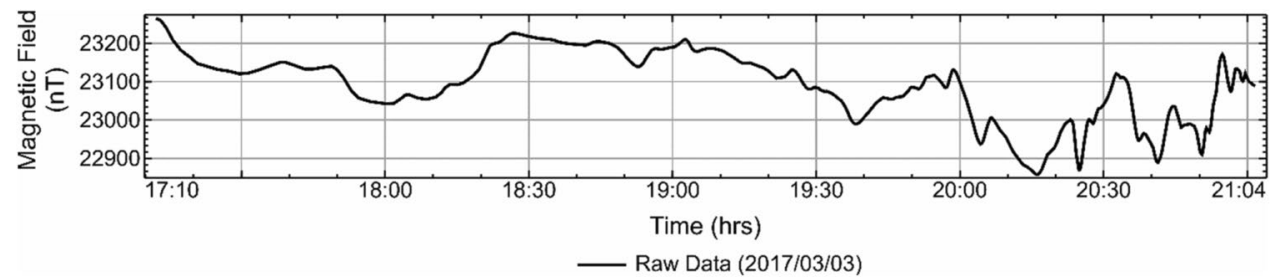

\section{Continental shelf near Mamanguá (RJ): October 6th to 7th, 2017}

The magnetic data from Survey 4 was collected with Veliger II wooden boat between October 6th and 7 th, 2017 (Survey 4 in Fig. 1a). The magnetometer towfish had a $40 \mathrm{~m}$ payout cable. The survey lines had an irregular geometry to cover the Mamanguá ria in the best possible way (Fig. 1c). The average line spacing may vary from 300 to $400 \mathrm{~m}$, and the profiles covered approximately 145 linear $\mathrm{km}$ of magnetic data sampled at $2 \mathrm{~m}$ spacing. One raw magnetic profile acquired on October 7 th, 2017, is presented in Fig. 5.

\section{Methods of diurnal variation correction and its validation}

\section{Diurnal variation correction}

The most common procedures to correct the diurnal variation are: $(\mathrm{A})$ the use of a base magnetometer that registers the variation in the magnetic field, and (B) the use of reoccupation survey points obtained every few hours on the same day during the survey. Neither of these techniques is easily applied to marine data because of high ship costs and logistic, hence some adjustments are usually made to obtain this correction. Commonly, the base magnetometer 
Fig. 5 Magnetic profile of Survey 4-Continental shelf near to Mamanguá between Ubatuba city (SP) and Ilha Grande (RJ), acquired on October 7th, 2017

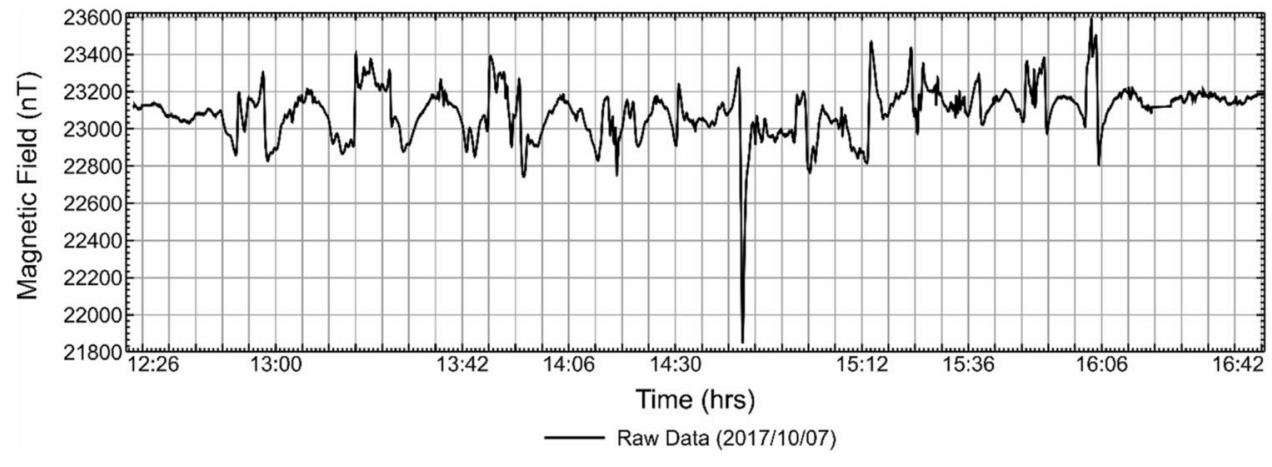

is located near the survey area, not as far as $80-100 \mathrm{~km}$ from data point collection (Breiner 1999; Reeves 2005; Telford et al. 1990; and many other authors). However, these are not a practical situation for marine survey and some alternatives are necessary to be pursued.

An alternative to the BASEMAG stations is the use of magnetic observatory data. In the studied cases presented here, we followed the method described by Buchanan et al. (1996) and used data from the Vassouras Magnetic Observatory (VSS/RJ) during survey days. Despite the VSS/RJ is located approximately $130 \mathrm{~km}$ from the Survey 4, $180 \mathrm{~km}$ from the Survey 3, $280 \mathrm{~km}$ from the Survey 1, and $250 \mathrm{~km}$ from the Survey 2 (Fig. 1a), we used the nearest observatory possible to assess this correction. In order to compare how the observatory data can be effective to correct the diurnal variation, we used the crossing points of these surveys to perform the data quality control analysis, and also use base magnetometer data when available.

The diurnal corrections imply subtracting the daily variation from the observed data. The daily variation comes from the magnetograms for the total magnetic field (Figs. 6 and 7), where it was used a value of 23,280 nT for the year 2017 and 23,290 nT for the year 2018, as average values for VSS/RJ. These average values were established visually using the point when the magnetic field curve starts to rise showing the diurnal perturbation, and they represent the total magnetic field at the station without the perturbation of the diurnal variation. The difference between the years may be related to the secular variation of the magnetic field, and even it is not the best mean value for the station, it would not imply some uncertainty for our analysis. The observed marine data was previously corrected with spikes removal and very high amplitude noise smoothing before diurnal variation correction. The procedure is the same for diurnal variation obtained from a BASEMAG or a magnetic observatory. At the end of this process, we have two datasets: (1) observatory corrected data for Surveys 1 to 4, (2) BASEMAG corrected data for Surveys 3 and 4.

For the reoccupation stations, it was selected all crossing points in the four survey areas. We calculated the
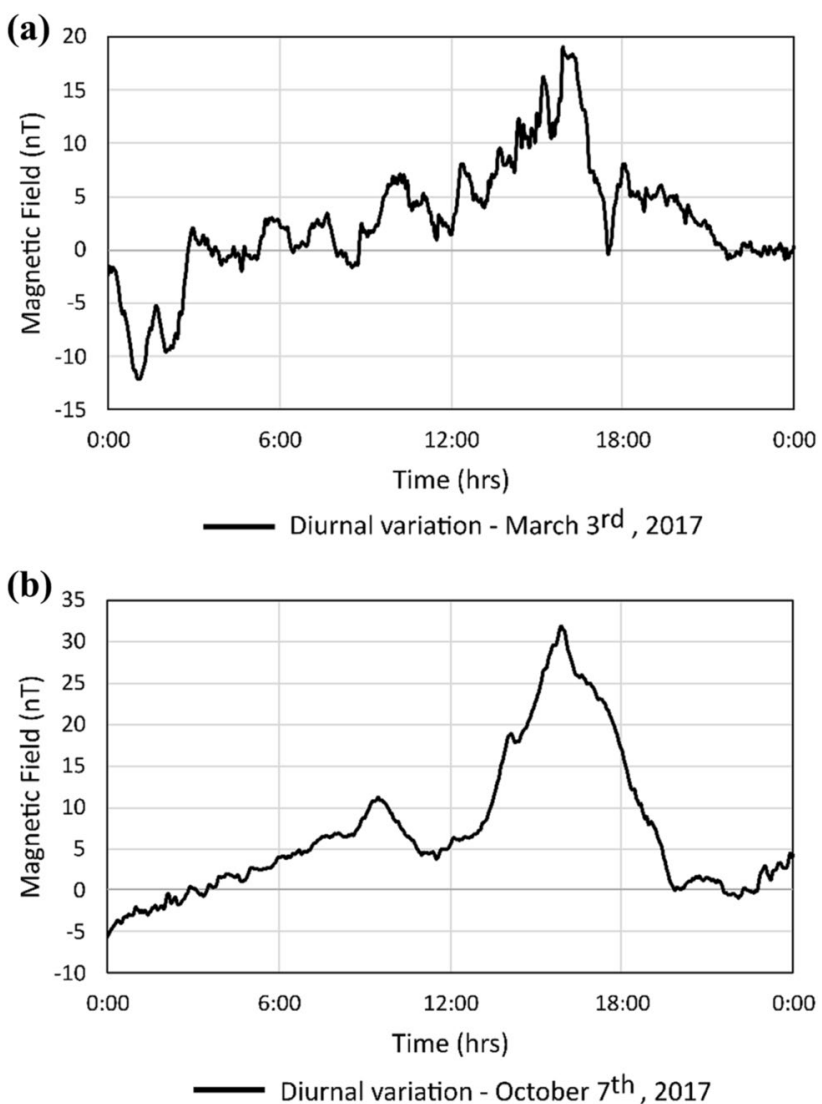

Fig. 6 Diurnal variation of the Vassouras Magnetic Observatory (VSS/RJ) with the measurement hour (UTC), on a March 3rd, 2017, during Survey 3, and b October 7th, 2017, during Survey 4. The diurnal variation was calculated by assuming $23,280 \mathrm{nT}$ as the mean value of the magnetic total field and reduced from the VSS/RJ magnetogram. Notice that the graphics shows a general common behavior, despite the high frequency noise that contaminated graphic a

difference at the crossing points of the raw data and after the diurnal variation from VSS/RJ was applied, then, we compared the differences between them. Although the reoccupation was not used for diurnal variation correction, it served as a measure of the validation of the correction using VSS/RJ. 


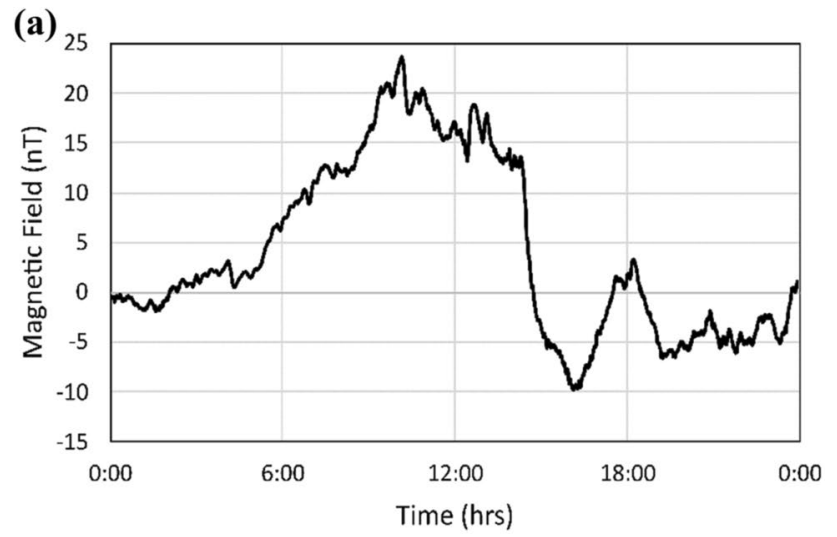

Diurnal variation - January $21^{\text {st }}, 2018$

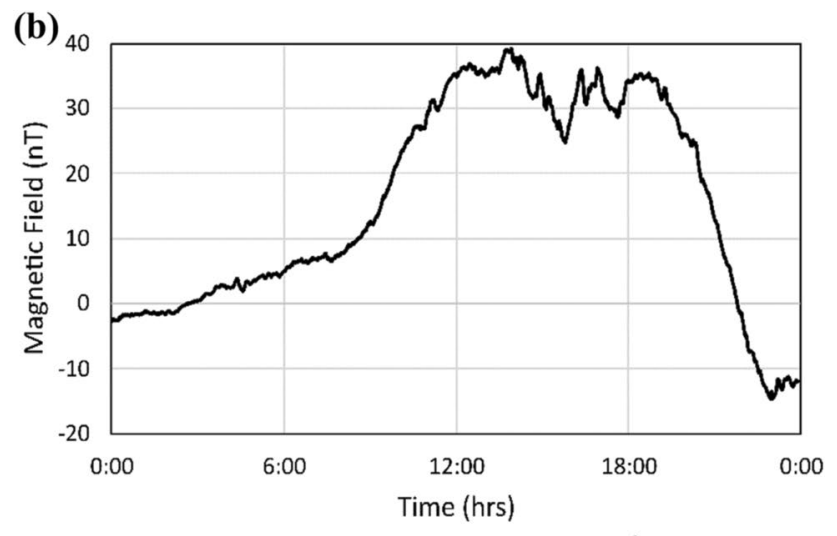

Diurnal variation - January $24^{\text {th }}, 2018$

Fig. 7 Diurnal variation, observed on January a 21st and b 24th, 2018, at Vassouras Magnetic Observatory (RJ) with the measurement hour (UTC). The diurnal variation was calculated by assuming $23,290 \mathrm{nT}$ as the mean value of the magnetic total field in VSS/RJ for the year of 2018 and reduced from the VSS/RJ magnetogram. Notice that the magnetometers present similar features of the observed in Fig. 6b, including the signal amplitude

\section{Statistical evaluation}

The Pearson's Correlation ( $r$, Eq. 1$)$ shows the linear relationship between two variables and how well a straight line adjusts through a data set (Figueiredo Filho and Silva Júnior 2009). Furthermore, it was performed to evaluate and validate the quality of the data by estimating the correlation between each of the magnetic survey data. This calculation was made on the statistical program Past 4.02.

$r=\frac{1}{n-1} \sum\left(\frac{x_{i}-\bar{x}}{S_{x}}\right)\left(\frac{y_{i}-\bar{y}}{S_{y}}\right)$

where $n$ is the total number of samples; $x_{i}$ and $y_{i}$ are respectively the values of variables $x$ and $y$ at the point $i ; \bar{x}$ and $\bar{y}$ are variable means; and $S_{x}$ and $S_{y}$ are the related standard deviation.

\section{Results}

\section{Calm and storm days in the data}

The diurnal variation values at VSS/RJ for the days of Surveys 3 and 4 assumes 23,280 $\mathrm{nT}$ as the mean value of the magnetic total field in the year of 2017 (Fig. 6). This value was considered as an average magnetic field, and it was removed from the others to obtain the diurnal anomaly of that day. According to SpaceWeatherLive.com, a magnetic storm occurred on March 1st, 2017, and maybe that is why the observatory magnetic signal was so chaotic, having so many high frequencies anomalies on March 3rd, 2017 (Fig. 6a). In the meantime, the observatory data behaved more like a Gaussian on the other dates, which is normally expected for diurnal variation, showing a maximum between 10 and $17 \mathrm{~h}$ (Figs. 6b and 7).

The magnetic storm interference observed on the magnetogram of March 3rd is characterized by the nonsmoothness curve and this may prevent us to use this particular survey day because it cannot express the real magnetic behavior generated by magnetic sources, and possibly showing non-existing anomalies. Nevertheless, we used this data to apply the diurnal correction even if it has worsened the signal in a few points comparing to the majority of survey data.

As observed in Figs. 6 and 7, VSS/RJ presents a diurnal variation of circa $50 \mathrm{nT}$, varying from -18 to $38 \mathrm{nT}$ around the assumed value for the observatory. In general, the magnetic field has a higher amplitude from 11:00 to 18:00, with a rapid fall after it. The increase in the daily variation between 6:00 and 12:00 is smooth.

The comparison between BASEMAG data of Surveys 3 and 4 with the VSS/RJ shows that the variation in the magnetic field was quite similar presenting differences less than $4.5 \mathrm{nT}$ for both survey dates (Fig. 8). Hence, the use of VSS/RJ data for correct diurnal variation along the Brazilian coast at a distance of around $450 \mathrm{~km}$ could be done with no harm for magnetic calm days.

The magnetic profiles with the raw and corrected data either by BASEMAG and/or VSS/RJ of the Surveys 2, 3, and 4 are shown in Fig. 9. Then, we notice a good performance of the correction done mainly in Survey 2, where the profile data tends to reduce its values at the beginning of the solar influence after 8 am (Fig. 9a). The raw data in the profile of Survey 3 is similar to the corrected by VSS/RJ data, so it is not possible to identify the red line in Fig. 9b. Besides, the corrected data by the BASEMAG assumes slightly higher values for the magnetic field comparing to the VSS/RJ correction, during the night, when the solar influence on the data tends to zero (Fig. 9b). This difference may be related to the average value chosen for 

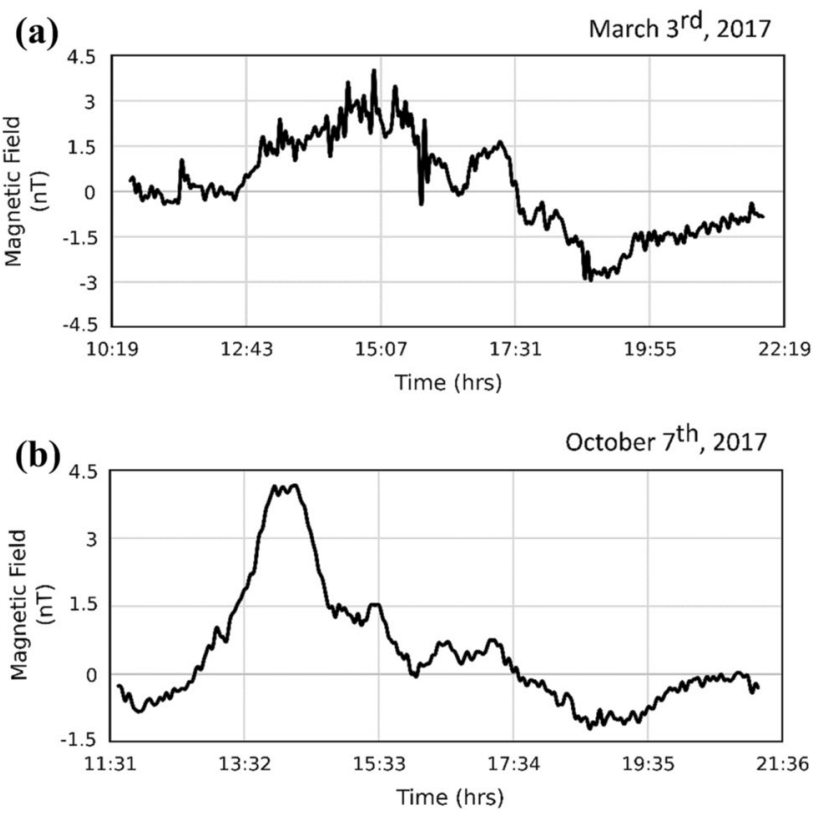

Fig. 8 Magnetic field difference between Vassouras Magnetic Observatory (RJ) and BASEMAG data on a March 3rd, and b October 7th, 2017, correspondingly to Surveys 3 and 4, respectively, with the measurement hour (UTC)

the location and day of the observatory station, although we kept the same value for another survey realized in 2017 , since it was the survey that happened at the end of a magnetic storm. Finally, the profile of the Survey 4 (Fig. 9c) did not seem to change much in general by both corrections.

\section{Crossing points technique}

All the crossing points acquired in the studied surveys are presented in Fig. 10. The Surveys 2, 3, and 4 have a considerable number of crossing points which collaborates with this analysis, since they were done in a small area with the objective of delimitating the anomalies (Fig. 10). However, the Survey 1 has only 2 crossing points since it is a survey formed by two long profiles (Fig. 10), from coast to slope and the return to Santos coast, while the ship was navigating to the slope survey area (Survey 2 in Fig. 1a).

We should emphasize here that Surveys 3 and 4 had a base magnetometer (Fig. 1a). For Surveys 1 and 2 it was not established a BASEMAG because of the long distance between the port and the survey areas, and the difficulty to leave a magnetometer in a region without magnetic disturbances, since the only area was available for use was the port of Santos. In the Survey 4, the crossing points were the result of the navigation of a small boat in a small area (Fig. 10). The crossing points for Survey 2 resulted from interesting signal observed in the sonar data during the cruise, while for the profiles the ship tried to do exactly the same profile azimuth and location in both ways, with some parts coincident and others slightly out of place (Fig. 10). In neither of the cruises studied here, there was a priori any expectation or will on getting crossing points, and they all resulted from random positions driven by the logistics at the sea.

When comparing the values of the magnetic field in these crossing points, with and without diurnal correction, the average difference of the corrected data varies from 1.6 to $0.05 \mathrm{nT}$, while the average of the uncorrected data varies from 4.4 to $0.36 \mathrm{nT}$ (Fig. 11). The average standard deviation for the corrected data is less than half of the value compared with the raw data. Comparing the surveys that had diurnal correction using VSS/RJ and BASEMAG, regarding to Survey 4, we notice that BASEMAG correction is slightly superior, with the standard deviation (Std dev.) corresponding to a reduction of $59 \%$ of the Std dev. of the raw data, while for the VSS/RJ, the reduction was 37\% (Fig. 11). For Survey 3, the reductions in the Std dev. were 57\% and $61 \%$ for BASEMAG and VSS/RJ, respectively, almost the same reduction but inverse of the one observed in Survey 4 case (Fig. 11). Then, we can observe an improvement of the data after correction by both BASEMAG and observatory VSS/ RJ in all surveys. This is less clear in Fig. 11 for Survey 1 where there are only two crossing points, but even this dataset showed some improvement.

\section{Pearson's correlation between uncorrected and corrected data}

The Pearson's correlation (Eq. 1) applied on each survey allowed the comparison of the values acquired at a different time from the same location, as known the crossing points. Table 1 shows the Pearson's Correlation results of the uncorrected data and corrected data both by the observatory VSS/ $\mathrm{RJ}$ and the BASEMAG in the surveys that had it. The $r$ value is highly greater than 0.9 , but it is slightly higher for the corrected data, with the exception of Survey 1, but in this case the numbers of crossing data points are very small. This corroborates the idea of the crossing points have closer values after the diurnal variation correction, made with BASEMAG or magnetic observatory data.

\section{Discussion}

\section{Analysis of the diurnal variation correction}

The comparison at the crossing points shows that the corrected data got closer from each other, approaching to zero, mainly in the Surveys 2, 3, and 4 (Fig. 11). This corroborates with Pearson's Correlation results (Table 1), which presents an improvement in the correlation of the data after 
Fig. 9 Magnetic profiles as a function of time representing each survey area: a Survey 2-Slope continental near Santos (SP) on January 23rd, 2018, b Survey 3-Continental shelf near to Ubatuba (SP) on March 3rd, 2017, and c Survey 4-Continental shelf near to Mamanguá ria (RJ) on October 7th, 2017. The raw data is in red, the corrected by Vassouras Observatory (VSS/RJ) is in blue, and the corrected by base magnetometer (BASEMAG) is in green
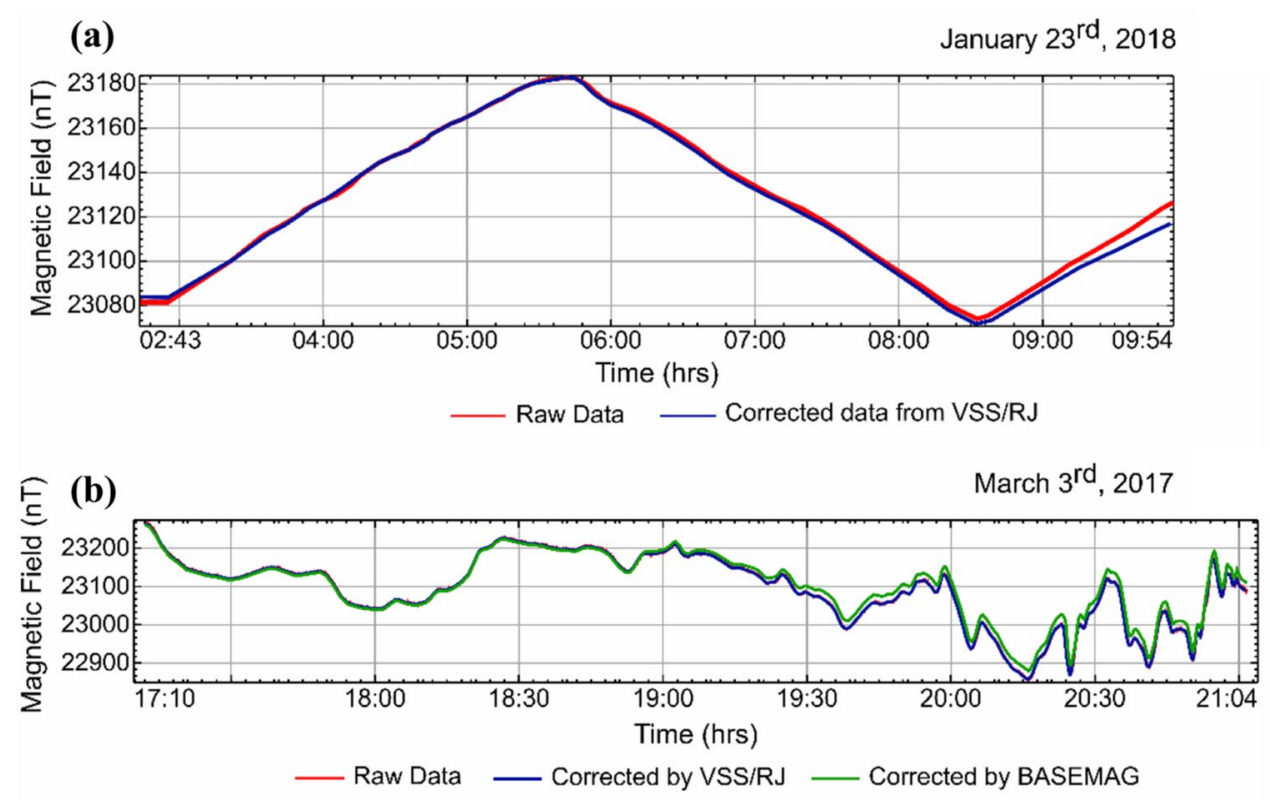

(c) October $7^{\text {th }}, 2017$

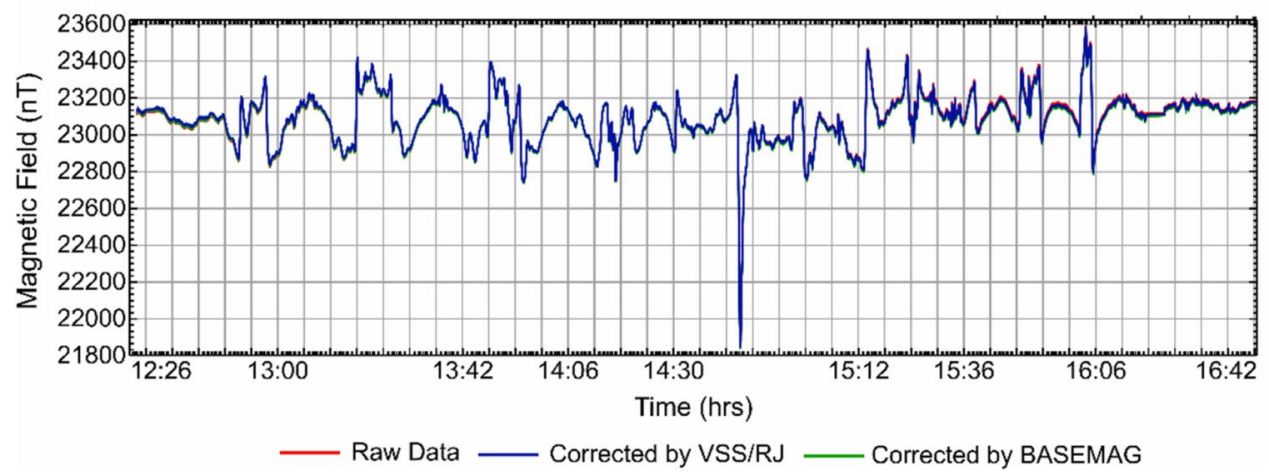

the diurnal variation correction, seen by the value approximating to 1 .

It is important to emphasize the comparison in the correction of data using a BASEMAG and the magnetic observatory (VSS/RJ in that case). This approach was done in the Surveys 3 and 4, where there was a BASEMAG working. As expected, the correction performed by BASEMAG works better than the correction with VSS/RJ, since the BASEMAG is located closer to surveys. Despite that, the results of correction done by VSS/RJ were satisfactory, except for a few points where the difference between the crossing points got bigger. However, the VSS/RJ correction was similar to the BASEMAG correction in most of the crossing points (Fig. 11). Therefore, in surveys near the coast, where a BASEMAG is not available, we can use observatory data to perform the diurnal correction.

The Pearson's Correlation was done comparing the crossing points of the uncorrected data and the corrected data by the use of VSS/RJ and BASEMAG data (Table 1). In Surveys 2 to 4 , we saw an improvement of this correlation after diurnal correction, either by VSS/RJ or BASEMAG data. In the Survey 3, the VSS/RJ and BASEMAG data correction does not seem to change much on the correlation results, and the values are almost the same. About the Survey 4, the BASEMAG correction has the best results, because of the great number of crossing points used to perform the comparison between values, but the correlation resulted after both corrections was very good.

In the Survey 1, Pearson's Correlation also does not seem to change, probably due to a small number of crossing points used for checking the method (Table 1; Fig. 10). However, we observed an improvement in the data at some of these points, mainly at $425 \mathrm{~km}$ (Fig. 11). Owing to that result, we performed a more detailed analysis of data from this survey. The raw profiles L1 and L2 were plotted together with their respective diurnal variation corrected profiles (Fig. 12a and b), and it was made a comparison between them to evaluate the correction (Fig. 12c and d). Regarding Profile L1, the correction caused a major influence on data, mainly between 445 and 515 km (Fig. 12a 


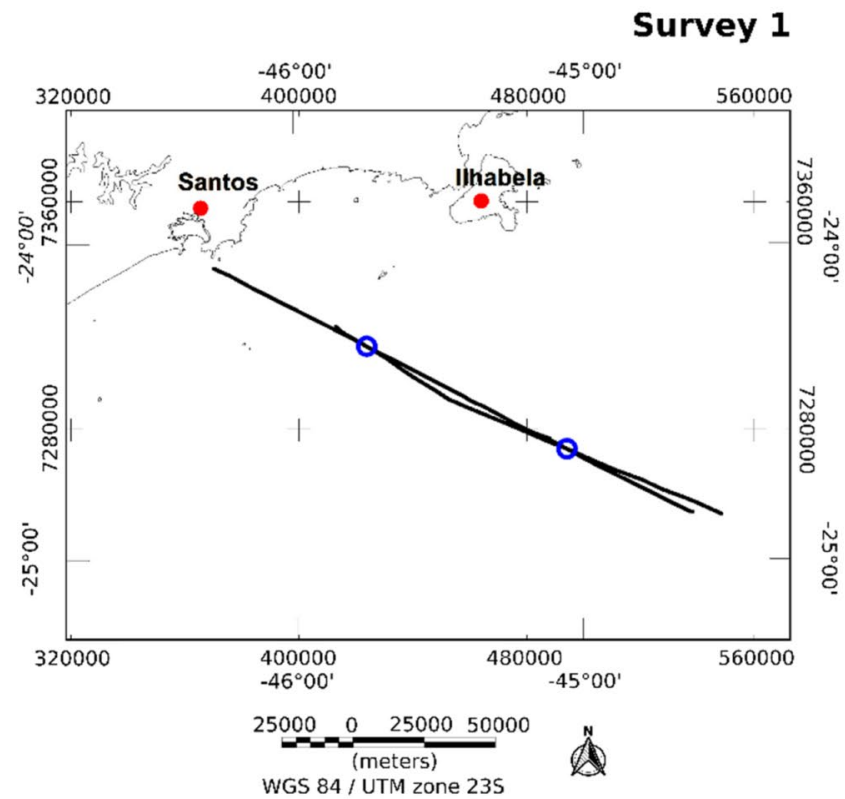

Survey 3

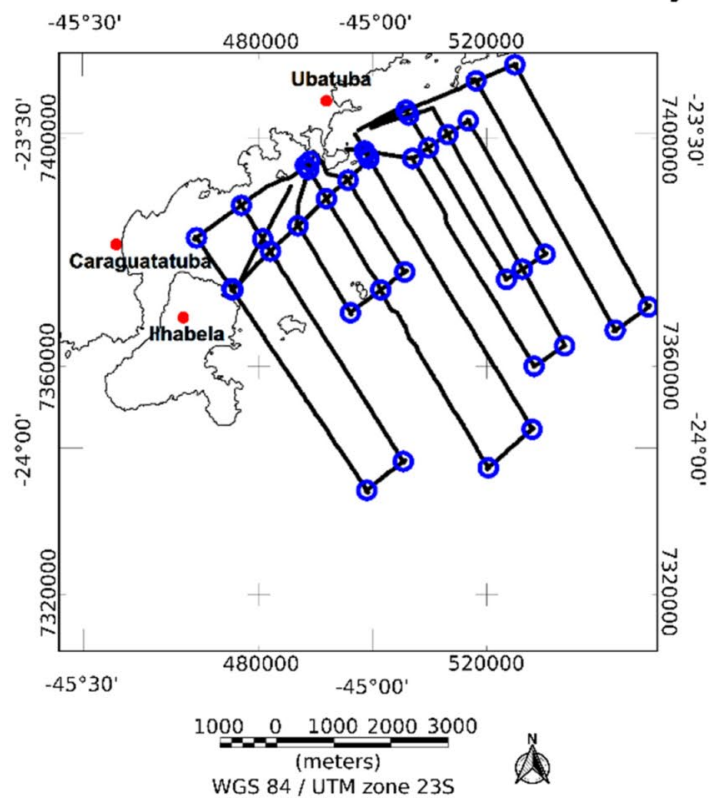

Fig. 10 Survey areas with all the crossing points marked in blue. Survey 1 is the continental shelf survey near Santos coast (SP) with 2 crossing points, Survey 2 is the continental slope survey near this last

and c). Besides that, the difference between raw and corrected data in other regions are not greater than $10 \mathrm{nT}$, which seems to suggest that the diurnal variation did not influenced much on data given the time of acquisition (Fig. 2a) and the minimum of diurnal influence (Fig. 7a). Concerning to profile L2, the correction acts mainly between $\mathrm{km} 410$ and 445 (Fig. $12 \mathrm{~b}$ and d), where the diurnal effect starts to influence the data given the time of acquisition (Figs. $2 \mathrm{~b}$ and $7 \mathrm{~b}$ ). Furthermore, the diurnal

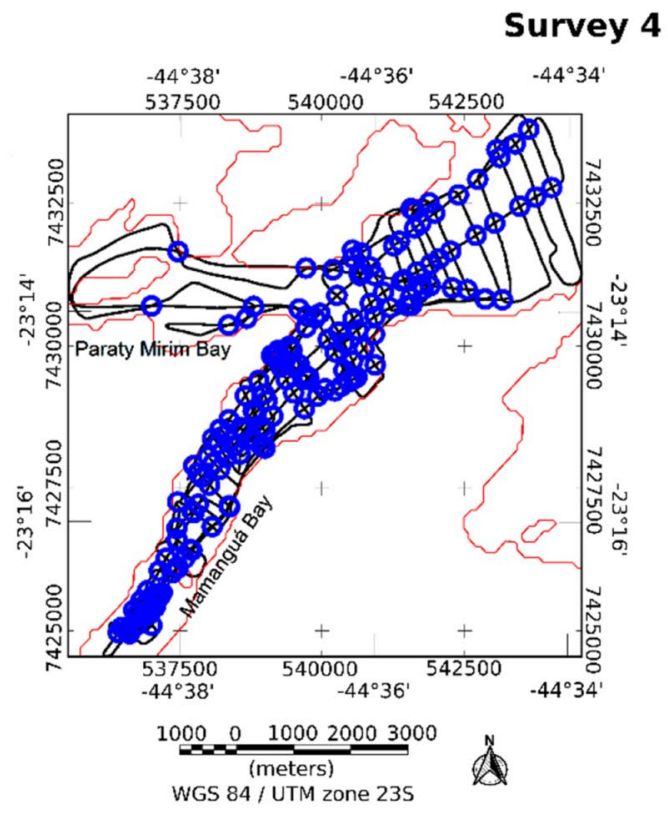

Survey 2

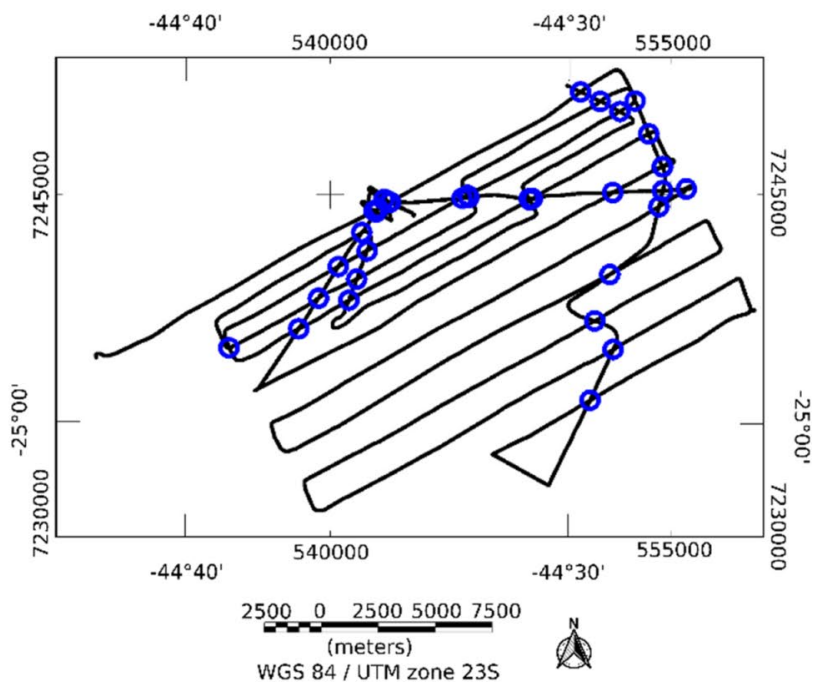

Survey 4

one with 40 crossing points, Survey 3 is the Ubatuba survey with 39 crossing points, and Survey 4 is the Mamanguá survey totaling 171 points crossing points

variation loses its influence along with the profile once most of it was acquired during the night.

\section{The South Atlantic Magnetic Anomaly and the diurnal variation}

An important feature of the Earth Magnetic Field present in the southeast Brazilian coast is the South Atlantic Magnetic Anomaly (SAMA). The origin of SAMA is still a debate 
Survey 1

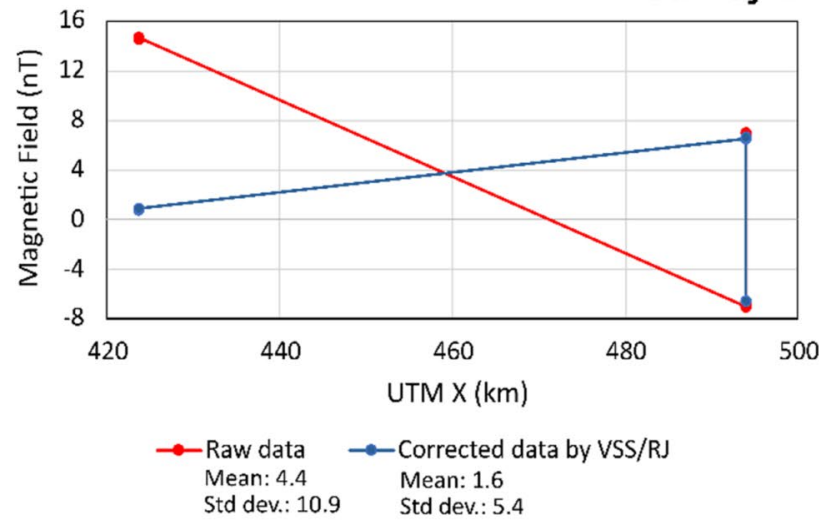

Survey 3

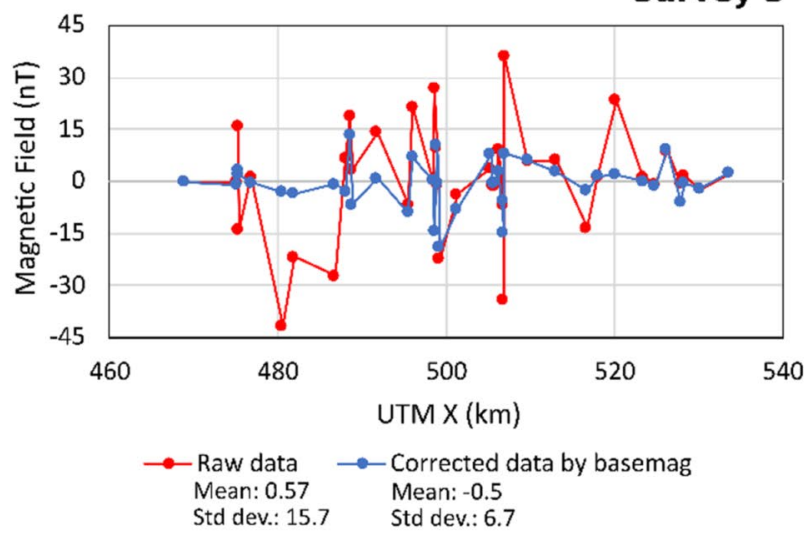

Survey 4

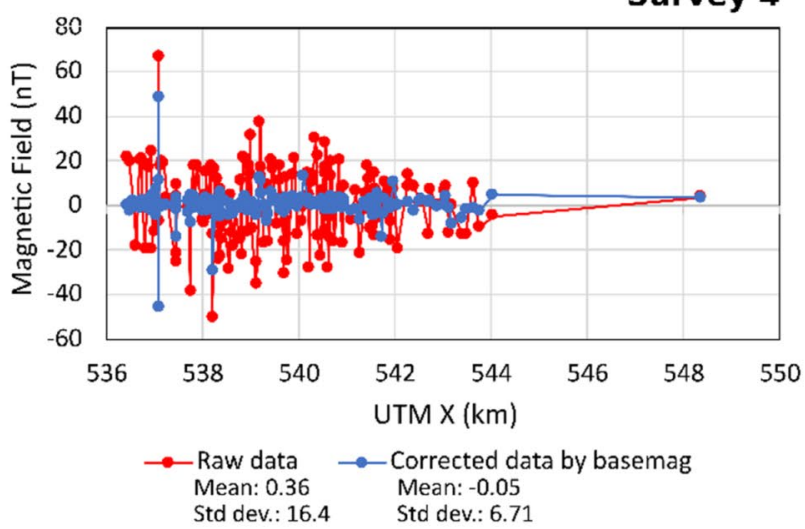

Fig. 11 Difference of magnetic field in the raw data (red) and the corrected data (blue), with the mean and standard deviation values, at all of the crossing points found in the designated survey areas. Survey 1 is the continental shelf survey near Santos coast (SP) with the corrected data done by Vassouras Observatory (VSS/RJ). Survey 2 is

topic, but one of the most accepted hypotheses for its origin is that it can be related to reverse fluxes in the external core under the South Atlantic Ocean (Hartmann and Pacca 2009). The SAMA is nowadays located between South America and South Africa (Fig. 13; Hartmann and Pacca 2009), and is characterized by a particularly low total field intensity, with

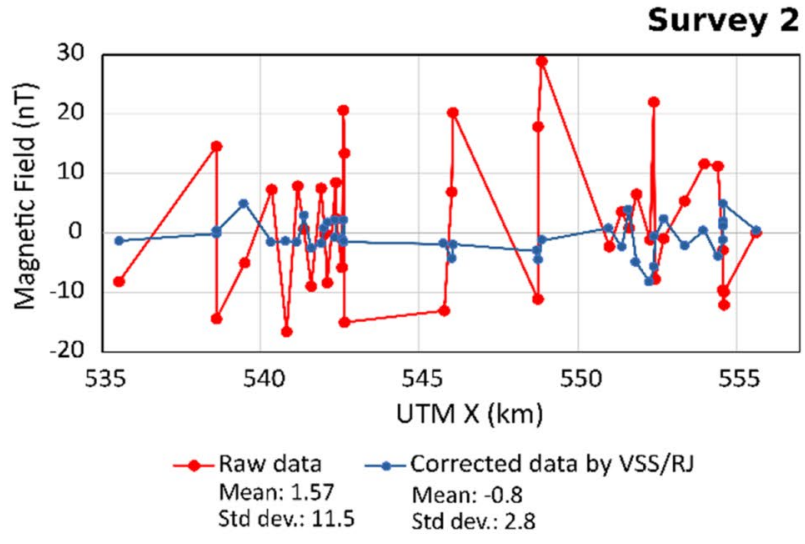

Survey 3

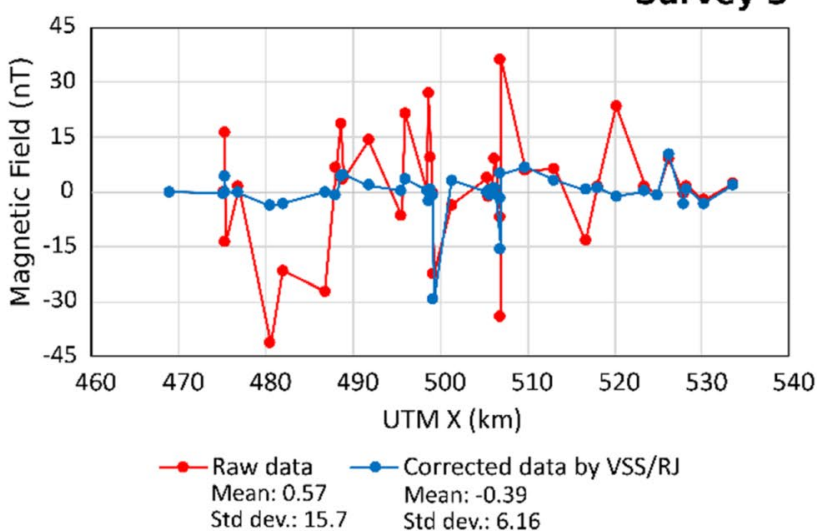

Survey 4

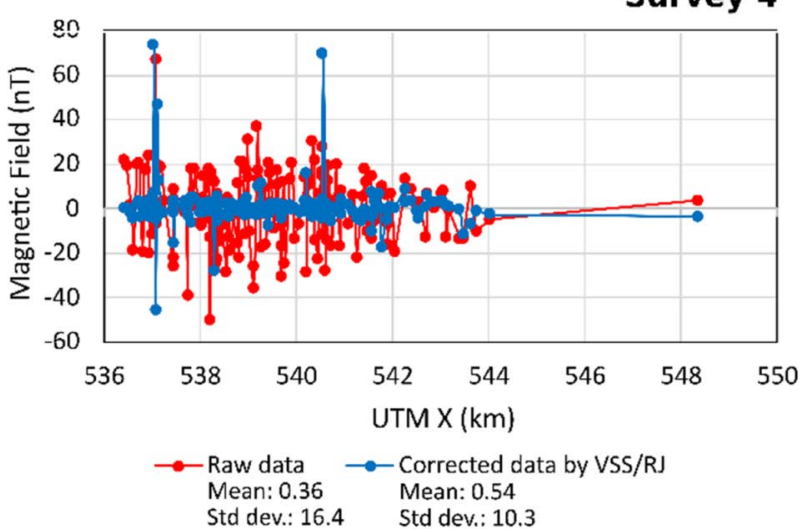

the continental slope survey near this last one with the corrected data also done by VSS/RJ. Survey 3 is the Ubatuba survey with the corrected data done by base magnetometer (BASEMAG) and by VSS/ RJ. Survey 4 is the Mamanguá survey with corrected data done by BASEMAG and by VSS/RJ

a minimum value of about $23,000 \mathrm{nT}$ in circa $700 \mathrm{~km}$ inland from the coast of Southern Brazil (Heirtzler 2002).

This feature is relevant for this work since it presents the lowest value for the magnetic total field, which could indicate a region of high-intensity cosmic radiation of space near Earth with the entrance of high-energy particles in the 
Table 1 Pearson's Correlation of raw data and diurnal corrected data, using VSS/RJ and BASEMAG data at the crossing points in each survey

\begin{tabular}{llll}
\hline Survey location & Uncorrected data & $\begin{array}{l}\text { Corrected } \\
\text { data by VSS/ } \\
\text { RJ }\end{array}$ & $\begin{array}{l}\text { Corrected data } \\
\text { by BASEMAG }\end{array}$ \\
\hline
\end{tabular}

\begin{tabular}{llll}
\hline Survey 1 & 0.9818 & 0.9809 & - \\
Survey 2 & 0.9643 & 0.9975 & - \\
Survey 3 & 0.9899 & 0.9984 & 0.9981 \\
Survey 4 & 0.9829 & 0.9911 & 0.9971 \\
\hline
\end{tabular}

The value of $r=1$ corresponds to a maximum correlation. The Survey 1 is the continental shelf near Santos coast (SP). The Survey 2 is the continental slope near to the Survey 1 location. The Survey 3 is the continental shelf near Ubatuba coast (SP). The Survey 4 is the continental shelf near Mamanguá coast (RJ)

magnetosphere (Heirtzler 2002). These particles are directly related to the diurnal variation origin process and can influence more easily on the magnetic data acquired.

Thus, we decide to compare VSS/RJ $\left(22.4^{\circ} \mathrm{S}, 43.65^{\circ} \mathrm{W}\right)$ variation with other observatories outside the SAMA to verify its influence (Table 2). We use data from King Edward Point Magnetic Observatory (KEP, $54.282^{\circ} \mathrm{S}, 36.49^{\circ} \mathrm{W}$ )

(a)
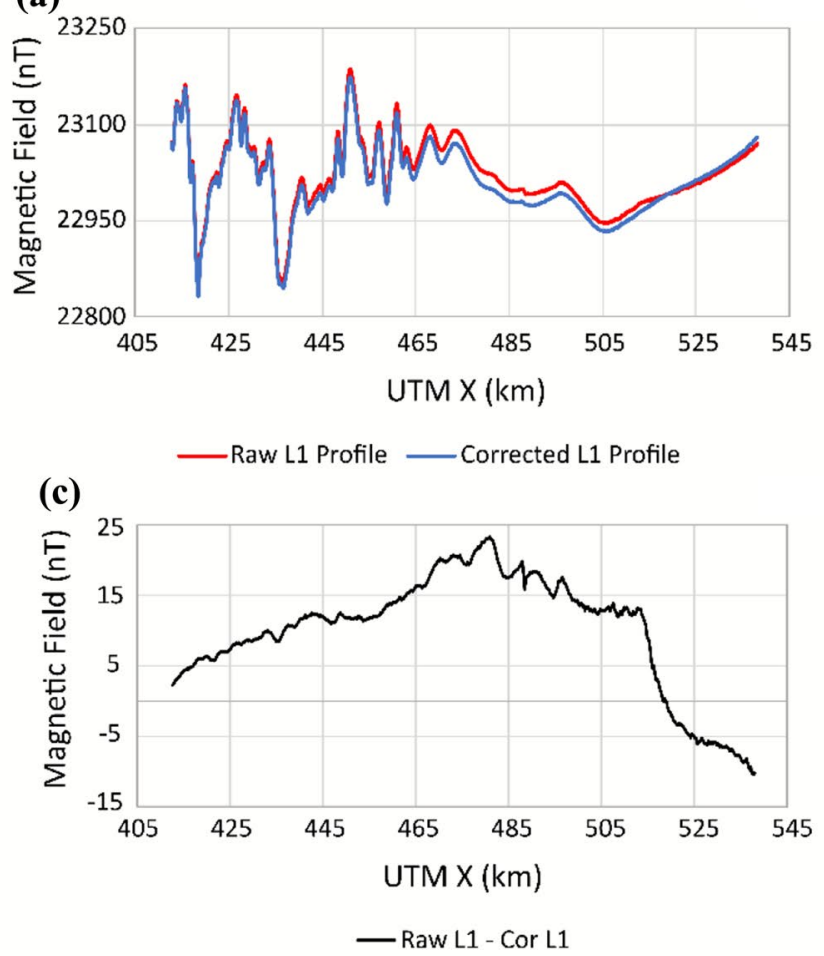

Fig. 12 Variation of the magnetic field as a function of distance (UTM X in kilometers), where $\mathbf{a}$ is the comparison between the raw L1 profile in red and diurnal variation corrected L1 profile in blue, b is the comparison between the raw L2 profile in red and diurnal variation corrected $\mathrm{L} 2$ profile in blue, $\mathbf{c}$ is the difference between raw located north of the British Antarctic Survey/South Georgia government base, at the foot of Mount Duse; the Port Stanley Magnetic Observatory (PST, $51.704^{\circ} \mathrm{S}, 57.93^{\circ} \mathrm{W}$ ) at Sapper Hill, Falkland Islands; and Akademik Vernadsk Base Observatory (AIA, $65.25^{\circ} \mathrm{S}, 64.25^{\circ} \mathrm{W}$ ) at Argentine Islands. KEP and PST are at the skirts of the SAMA, and AIA is south of SAMA (Fig. 13).

The maximum and minimum values of the base magnetometer and VSS/RJ data were almost close to each other (Table 2) and also these curves are very similar (Fig. 14) due to the proximity between them, located at almost the same latitude. Comparing the difference between the maximum and minimum values with other magnetic observatories (Table 2; Fig. 14), it is clear that VSS/RJ shows a medium difference of $4.59 \pm 23.30 \mathrm{nT}$. When data from AIA on March 3rd, 2017, is excluded the average difference decreases to $-0.73 \pm 18 \mathrm{nT}$. Hence, the influence of the SAMA does not increase the diurnal variation in the area, at least compared with stations near the pole. This can also be seen in Fig. 14 for October 7th, 2017, in which we can notice that variations in amplitude is almost the same for all observatories but is circa $10 \mathrm{nT}$ higher at AIA at the peak of activity compared with the others, and that it is expected since it
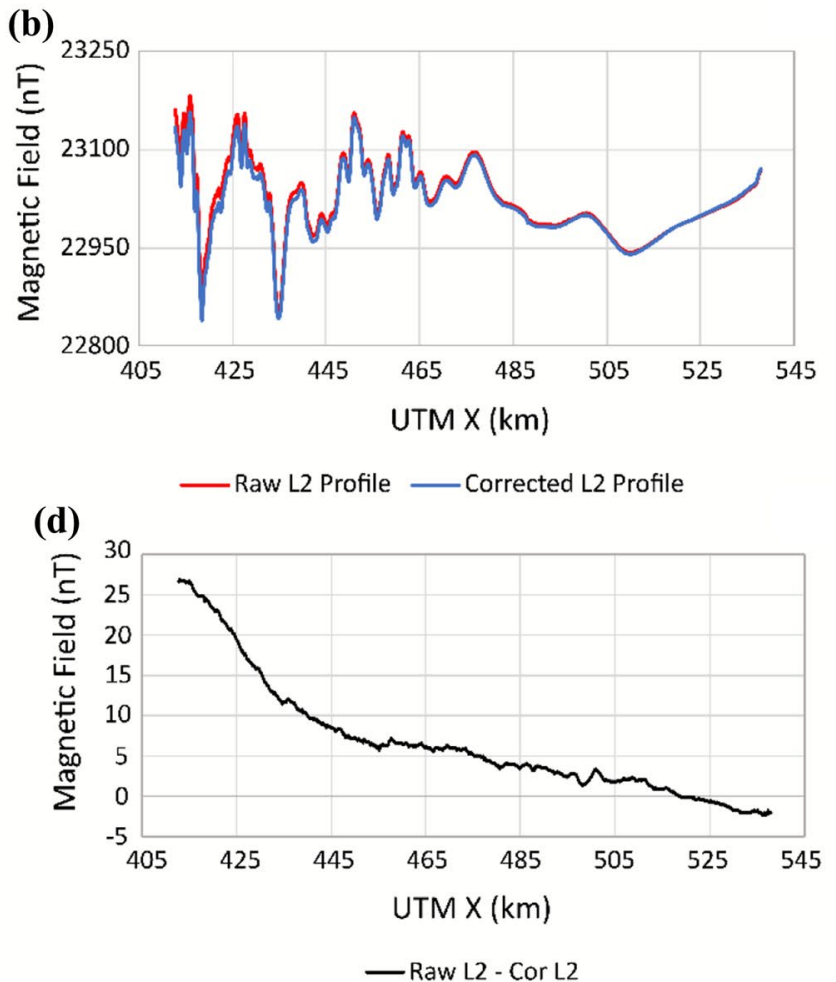

and corrected (cor) data of profile L1 in black, and $\mathbf{d}$ is the difference between raw and corrected (cor) data of profile L2 in black. The Profile L1 was acquired on January 21st and the Profile L2 on January 24th 


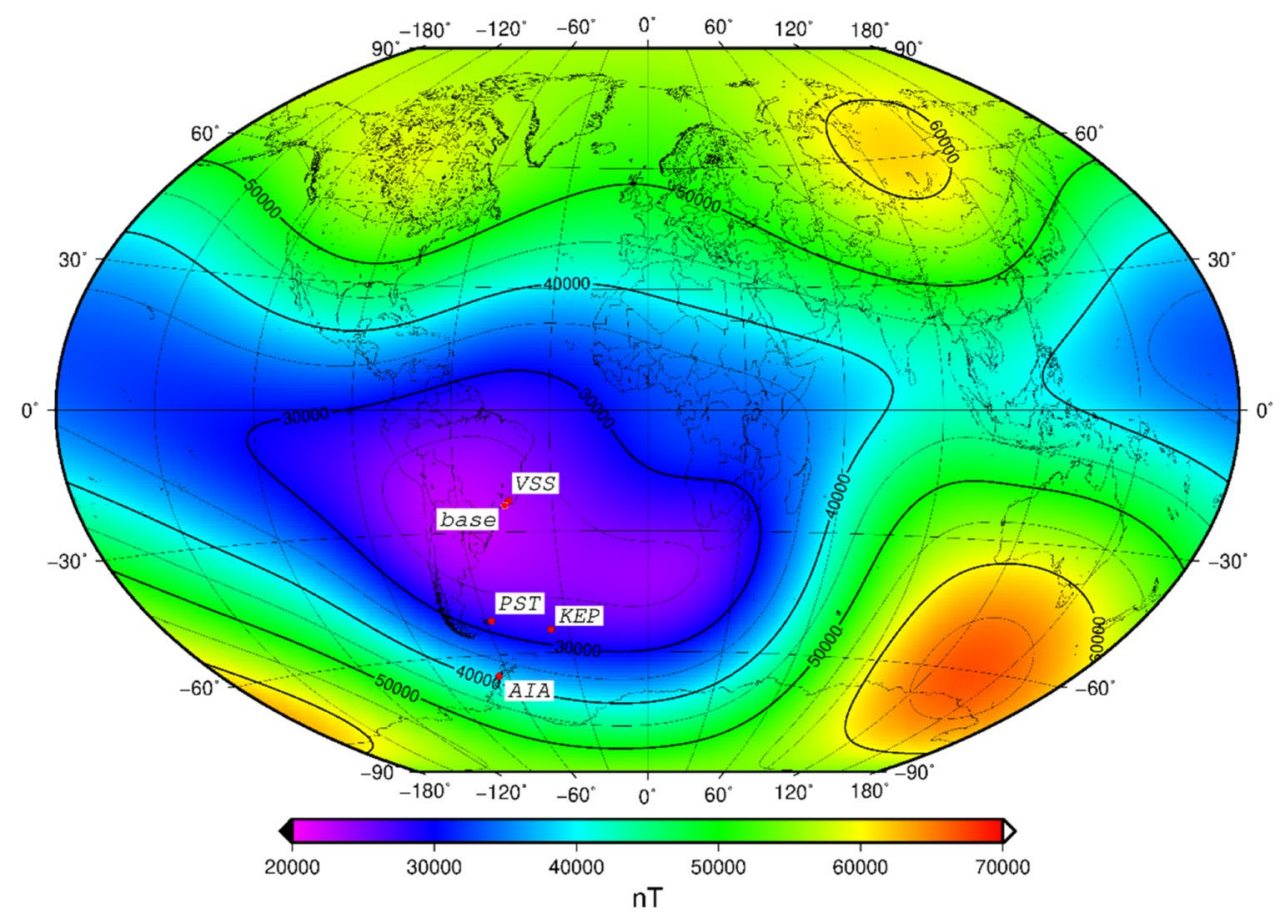

Fig. 13 Total intensity of the internal magnetic field in 2020, derived from the 13th generation of the IGRF (International Geomagnetic Reference Field). This dataset was obtained by National Geophysical Data Center (NGDC) site (https://www.ngdc.noaa.gov/geomag/ calculators/magcalc.shtml?useFullSite=true\#igrfgrid) and the map was made through The Generic Mapping Tools (GMT) software. The
SAMA (South Atlantic Magnetic Anomaly) influence is indicated by the dark blue color and the magnetic observatories are indicated by your initials, KEP the King Edward Point observatory, PST the Port Stanley Observatory, AIA the Akademik Vernadsk Base Observatory, and VSS the Vassouras Observatory. The base magnetometer location is approximately indicated by the word 'base'
Table 2 Maximum (MAX), minimum (MIN) and the difference between MIN and MAX (DIFF) values of the magnetic field (in nanotesla) at the base magnetometer (BASEMAG), Vassouras (VSS/RJ), Argentine Islands/ Akademik Vernadsky base (AIA), King Eduard Point (KEP) and Port Stanley (PST) Magnetic Observatories in study survey days

\begin{tabular}{|c|c|c|c|c|c|c|}
\hline Date & $\begin{array}{l}\text { MAX/MIN/ } \\
\text { DIFF values } \\
(\mathrm{nT})\end{array}$ & BASEMAG (nT) & VSS/RJ (nT) & $\mathrm{AIA}(\mathrm{nT})$ & $\mathrm{KEP}(\mathrm{nT})$ & PST (nT) \\
\hline \multirow[t]{3}{*}{ March 3rd, 2017} & MAX & 23,138 & 23,299 & $38,090.5$ & 27,811 & 28,308 \\
\hline & MIN & 23,119 & 23,279 & 38,018 & 27,783 & 28,257 \\
\hline & DIFF & 19 & 20 & 72.5 & 28 & 51 \\
\hline \multirow[t]{3}{*}{ October 7th, 2017} & MAX & 23,141 & 23,313 & 38,042 & 27,798 & 28,271 \\
\hline & MIN & 23,110 & 23,280 & 37,988 & 27,756 & 28,239 \\
\hline & DIFF & 31 & 33 & 54 & 42 & 32 \\
\hline \multirow[t]{3}{*}{ January 21st, 2018} & MAX & - & 23,314 & - & 27,784 & 28,261 \\
\hline & MIN & - & 23,280 & - & 27,736 & 28,238 \\
\hline & DIFF & - & 34 & - & 48 & 23 \\
\hline \multirow[t]{3}{*}{ January 24th, 2018} & MAX & - & 23,329 & - & 27,778 & 28,255 \\
\hline & MIN & - & 23,275 & - & $27,749.6$ & 28,235 \\
\hline & DIFF & - & 54 & - & 28.4 & 20 \\
\hline
\end{tabular}

is closer to the pole, where the field intensity is higher. All curves of Fig. 14 show some resemblance, although this is not a rule, as can be seen in the literature (Häkkinen et al. 2003; Oblekesle et al. 2013), since it depends on the observatory position regarding the magnetic field and season of the year (Cnossen et al. 2012; Lyatsky and Hamza 2001).
The Base (darker blue) and VSS/RJ (orange) shows a very similar curve, with some small difference, less than $10 \mathrm{nT}$, between 10:00 to 15:00. PST (light blue) AIA (gray) and KEP (yellow) shows a similar behavior from 11:30 to almost 14:30 when KEP starts a smooth decline in amplitude earlier than the other curves. We do not know why this happens, but 


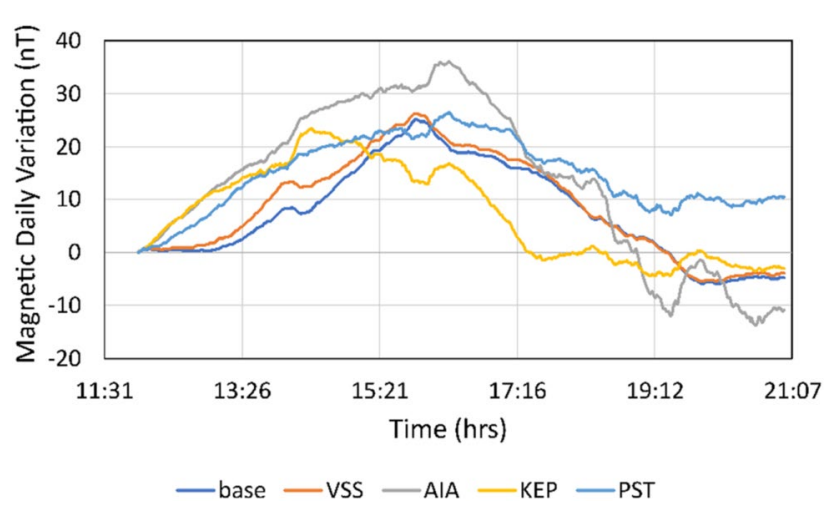

Fig. 14 Diurnal variation at magnetic observatories for October 7th, 2017, with the measurement hour (UTC). KEP the King Edward Point observatory, PST the Port Stanley Observatory, AIA the Akademik Vernadsk Base Observatory, VSS the Vassouras Observatory, and base is the base magnetometer. Notice that variations amplitude is almost the same in all observatories

we can speculate that it can be related to its longitude location (Oblekesle et al. 2013), compared with AIA and PST observatories that are closer in longitude (Fig. 13).

The diurnal variation may be affected by the tidal motion, causing changes in the magnetic field acquired in marine surveys (Hill and Mason 1962). Thus, the geomagnetic coast effect (Parkinson and Jones 1979) proposes the use of magnetic observatories around the world to correct the data of surveys near to them (Buchanan et al. 1996; Vacquier 1972). Moreover, it is possible to generate a diurnal curve from acquired data in low magnetic anomaly regions (Buchanan et al. 1996). Although we have not seen these effects in our data, this study ensures the effectiveness of this diurnal correction method that can be used worldwide with some cautions, using crossing points analysis in all near-coast study surveys, and comparing this result with the base magnetometer correction in two of them.

\section{Conclusion}

Considering the difficulty of removing the diurnal variation in marine magnetometric data, the use of magnetic observatories data can be helpful to improve the quality of data. The crossing points technique applied in this study was important to validate the correction and check the effectiveness of this process by comparing results after and before correction. Regarding the crossing points analysis, the Pearson's Correlation values were greater than 0.9 after diurnal variation correction, showing a significant correlation and the effectiveness of this process.

As mentioned before, one of the first effects that we must be careful about is the possibility of a magnetic storm event during the days of the survey, as it can severely influence the magnetic data. Despite the occurrence of this phenomenon close to the Ubatuba survey date (Survey 3 ), which may have had influenced the magnetic data acquired, the correction done on them was satisfactory.

In the continental shelf survey near Santos coast (SP) (Survey 1), where there are only a few crossing points, a complementary analysis was made to ensure the correction of the diurnal effects in the data. The residuals show an improvement in data after this correction.

The methods applied to perform the diurnal variation correction were successful, even when the magnetic observatory used for diurnal correction was located far from survey areas (less than $280 \mathrm{~km}$ ). Although we cannot calculate this correction by a BASEMAG in some of the study surveys, the use of nearby magnetic observatory data and an analysis of crossing points (applied in this study) were substantially important to perform the diurnal correction. Therefore, this work expects to help future near-coast marine surveys worldwide that do not have a stationary magnetometer to calculate the diurnal correction using observatory magnetic data.

Acknowledgements First, we all are grateful to the Captain, Officers, and Crew of the NOc Alpha Crucis and Veliger II, this work will not happen without their exceptional professionalism and devotion to the magnetic data acquisition process. Also, thanks to São Paulo State Research Funding (FAPESP) to academically fund some of these studies, scholarship to PPS and CORE project (processes 2018/19355-7 and 16/24946-9, respectively).

Open Access This article is licensed under a Creative Commons Attribution 4.0 International License, which permits use, sharing, adaptation, distribution and reproduction in any medium or format, as long as you give appropriate credit to the original author(s) and the source, provide a link to the Creative Commons licence, and indicate if changes were made. The images or other third party material in this article are included in the article's Creative Commons licence, unless indicated otherwise in a credit line to the material. If material is not included in the article's Creative Commons licence and your intended use is not permitted by statutory regulation or exceeds the permitted use, you will need to obtain permission directly from the copyright holder. To view a copy of this licence, visit http://creativecommons.org/licenses/by/4.0/.

\section{References}

Breiner S (1999) Applications manual for portable magnetometers. Technical Report, 1. Sunnyvale, CA 94066: Geometrics. https:// doi.org/10.6067/XCV8DJ5JD6

Buchanan SK, Scrutton RA, Edwards RA, Whitmarsh RB (1996) Marine magnetic data processing in equatorial regions off Ghana. Geophys J Int 125:123-131. https://doi.org/10.1111/j.1365-246X. 1996.tb06539.x

Cnossen I, Wiltberger M, Ouellette JE (2012) The effects of seasonal and diurnal variations in the Earths's magnetic dipole orientation on solar wind-magnetosphere-ionosphere coupling. J Geophys Res 117:A11211. https://doi.org/10.1029/2012JA017825

Figueiredo Filho DB, Silva Júnior JAD (2009) Desvendando os Mistérios do Coeficiente de Correlação de Pearson (r). Revista Política 
Hoje, Recife 18(1):115-146. https://doi.org/10.11606/issn.22374485.lev.2014.132346

Häkkinen LVT, Pulkkinen TI, Pirjola RT, Nevanlinna H, Tanskanen EI, Turner NE (2003) Seasonal and diurnal variation of geomagnetic activity: revised Dst versus external drivers. J Geophys Res 108(A2):13. https://doi.org/10.1029/2002JA009428

Hartmann GA, Pacca IG (2009) Time evolution of the South Atlantic magnetic anomaly. An Acad Bras Ciênc 81(2):243-255. https:// doi.org/10.1590/S0001-37652009000200010

Heirtzler JR (2002) The future of the South Atlantic anomaly and implications for radiation damage in space. J Atmos Solar Terr Phys 64(16):1701-1708. https://doi.org/10.1016/S1364-6826(02) 00120-7

Hill MN, Mason CS (1962) Diurnal variation of the Earth's magnetic field at sea. Nature 195:365-366. https://doi.org/10.1038/19536 $5 \mathrm{a} 0$

Lowrie W (2007) Fundamentals of geophysics. Cambridge University Press, Cambridge

Lyatsky W, Hamza AM (2001) Seasonal and diurnal variation of geomagnetic activity and their role in Sapce Weather forecast. Can J Phys 79:907-920. https://doi.org/10.1139/cjp-79-6-907

Melo JA, Marangoni YR, Jovane L (2019) Análise preliminar dos dados magnéticos do Saco do Mamanguá e da Enseada de ParatyMirim, Rio de Janeiro. Expanded Abstracts, 16 th International Congress of SBGf, Rio de Janeiro 6. https://doi.org/10.22564/ 16cisbgf2019.048.

Mohriak WU (2003) Bacias Sedimentares da Margem Continental Brasileira. Geologia, Tectônica e Recursos Minerais Do Brasil 3:87-94

Oblekezle TN, Obladazle SC, Agbo GA (2013) Day-to-day variability of $\mathrm{H}$ and $\mathrm{Z}$ components of the Geomagnetic Field at the African longitudes. ISRN Geophysics, 2013, article ID 909258, 7 p. https://doi.org/10.1155/2013/909258.
Panasyuk MI, Kuznetsov SN, Llazutin L, Avclyushin SI, Alexeev II, Ammosov PP, Antonova AE, Baishev DG, Belenkaya ES, Beletsky AB, Betov AV (2004) Magnetic storms in October 2003. Cosm Res. https://doi.org/10.1023/B:COSM.0000046230.62353. 61

Parkinson WD, Jones FW (1979) The geomagnetic coast effect. Rev Geophys 17:1999-2005. https://doi.org/10.1029/RG017i008p 01999)

Pereira MJ, Macedo JM (1990) A Bacia de Santos: perspectivas de uma nova província petrolífera na plataforma continental sudeste brasileira. Boletim De Geociências Da PETROBRAS 4(1):3-11

Reeves C (2005) Aeromagnetic surveys Principles, practice interpretation. Earthworks., Published by Geosoft (www. geosoft.com) 111

SpaceWeatherLive.com (2017) Top 50 geomagnetic storms of 2017. Retrieved January 12, 2020, from https://www.spaceweatherlive. com/en/auroral-activity/top-50-geomagnetic-storms/year/2017. html.

Telford WM, Geldart LP, Sheriff RE (1990) Applied geophysics. Cambridge University Press, New York

Vacquier V (1972) Geomagnetism in marine geology. Elsevier Publishing $\mathrm{Co}$, Amsterdam

Zhang Y, Sekine T, He H, Yu Y, Liu F, Zhang M (2016) Experimental constraints on light elements in the Earth's outer core. Sci Rep 6:22473. https://doi.org/10.1038/srep22473

Publisher's Note Springer Nature remains neutral with regard to jurisdictional claims in published maps and institutional affiliations. 